\title{
Shifting the Focus to East and Southeast Asia: A Critical Review of Regional Game Research
}

\author{
Phan Quang Anh ${ }^{1}$ D
}

Received: 20 February 2020 / Accepted: 4 February 2021 / Published online: 17 February 2021

(c) Fudan University 2021

\begin{abstract}
This paper examines the prominence of East and Southeast Asia as a focus of communications and game studies. The idea of going regional when researching video games comes from the fact that each locale has its trait to construct its gaming industry and gaming environment from which the gaming experience is also reflected differently. The reasons provided, ranging from the regional market's dynamic nature to the attention that the governing states have paid to the gaming industry, help place Asia-Pacific in general and East and Southeast Asia particularly in the global gaming juxtaposition where the other part is usually the Western countries. Examples that help highlight the rising prominence of the regions as the most potential areas are also considered. This review's findings indicate that East and Southeast Asia have gradually built up their reputation by actively joining the designing, processing, and distributing digital products system. Thus, the focus of future research on the regions should be more concerned with video gaming.
\end{abstract}

Keywords Creative industries · East asia game research · Game culture - Media governance southeast asia

\section{Introduction}

Asia-Pacific is known as the part of the world located in or near the western Pacific Ocean, which generally includes East Asia, South Asia, Southeast Asia, and Oceania. According to Hjorth and Chan (2009), the Asia-Pacific region should be conceived as a geopolitical and economic construct. Although the regions' economies are heterogenous with the mixture of both developed and developing countries, it is remarkable that most individual nations within the zone are emerging markets experiencing rapid growth and burgeoning economic prosperity. The global role

Phan Quang Anh

phanquang.anh@uzh.ch

1 Department of Social Anthropology and Cultural Studies (ISEK), University of Zurich (UZH), Andreastrasse 15, 8050 Zurich, Switzerland 
of the Asia-Pacific, especially East and Southeast Asia, has shifted dramatically since the region's financial crisis of 1997. Throughout this period, the region has witnessed the simultaneous rise of industrial, technological, and economic power with its developing role in the global gaming industries. Even though the financial market undoubtedly suffered from the crisis, the emergence of technology, namely commercial Internet services in countries such as Vietnam, has mitigated the financial crisis's harmful effects. Indeed, the gaming industry has facilitated the region's transformation of its economic and technological sectors into a global cultural capital as people are eager to adopt virtual life.

For the last two decades, the digital game has been known as a fast-growing industry, blossoming more than ever thanks to the emergence of the Internet, the stable and steady development of mobile platforms as well as the availability of numerous design utilities that facilitate the gaming production (Wolf 2015). In the twentieth century, the gaming industry was monopolized by major companies such as Microsoft, Nintendo, and Sony from the USA, Japan, and Europe. In recent years, there has been an industry shift where smaller players can gain a foothold in the global market because of accessibility factors provided by technology developments such as the Internet and mobile devices. The birth of the cyber community market, such as Google Play or App Store, even allows small teams to promote and market their ideas without being dependent on a complicated distribution system. A oneperson developer team is even possible, as seen from the cases of Flappy Bird in 2013 and Undertale in 2015. The same comment could also be applied to countries whose names could not be found on the map of gaming production in the past, like Vietnam or Thailand. Now, they have the opportunity to begin their history of producing video games, making their product appear on the shelves of game stores in other countries.

The belief that there is a division between the Western mode of gaming production and the Third World countries needs to be eradicated (Kerr 2006; Penix-Tadsen 2016; Schleiner 2020). Schleiner, with her optimistic viewpoint, noted that not only young North American people but also children in faraway regions in Latin America or Africa own the right and have the possibility of accessing games consoles and/or computer games. In the case of developing countries, Shaw (2013) has suggested that we should shift our orthodox view from the USA stores to small arcades and Internet cafés, from authorized retailers to stores where devices are imported unofficially and modded to read pirate version of games that could be bought from a vendor on the street, and from hi-end consoles to mobile phones which can be purchased at affordable price. It is worth noting that by mentioning these marginalized topics, it does not mean piracy should be tolerated. It only suggests that instead of looking at partially axiomatic things, changing the angle to observe used-to-be underrated places could bring in novel insights. We can obtain a different perspective in researching digital gaming culture when we focus on the conditions visible in countries in the Southern hemisphere (Latin America and Southeast Asia) where people have their ways of dealing with poverty, the low quality of living conditions, and access to digital entertainment at the same time (Schleiner 2020).

East and Southeast Asia are geographically defined as the east and southeastern regions of Asia, consisting of six states in East Asia and eleven states in Southeast Asia 
(Finlayson 2019). By analyzing the gaming industry of Asia-Pacific with a strong focus on East and Southeast Asia in the contemporary era, Hjorth (2011) asserted that video games are not merely a form of entertainment. In fact, gaming activities have become representative of the virtual life in which contemporary social relations, online communities, and media engagement take place, reflecting human life in another dimension. With the rise of the dynamic East Asian countries currently led by a fully ambitious China and the aspiration to more deeply and broadly integrate showcased by Southeast Asian countries (as a part of the global South-a novel yet challenging topic), Schleiner (2020) posed a chain of questions: From a game research perspective, beyond acknowledging and making visible the players and spaces for digital gameplay, what more can we learn from the usually underrated regions? Could it be premature to assert that digital game culture is a one-way flow, exported from enterprises and studios based in the technologically upscale West to the East and from the North to the Southern part of the globe? From that point, Schleiner (2020) goes on with a central question: Does the gaming landscape in Asia, therefore, always play the role of a late racer when catching digital game trends that seem to be set by more game-savvy nations like the USA and European countries where games are no longer played in venues like arcades and Internet cafés? That leads to my supplemental question, which might flip that issue of speed: How can East and Southeast Asia be considered "late" or "slow" when the widespread usage of mobile phones and the increase in personal devices served as the basis to illustrate the aspiration of modernization have provided these two regions with an unprecedented scenario, not to say that they are growing fast more than ever when it comes to several aspects such as eSports? These questions have generally given me the impression that it is time to shift the focus of game research to East and Southeast Asia, seriously considering that this part of the planet has been posing some new issues worth paying attention to.

This paper aims to explore two aspects. First, it extends the boundaries of game research by discussing some strongly held beliefs in game studies, with much of them have either been set in Western contexts or generalized based on studies that focus on the Western settings, and argues why we need to think about the gaming industry, the market, and the players beyond the epitome set by the Western perspective. Second, it explains why East and Southeast Asia, as the focus of this study, needs attention from experts who conduct game-related research. The finding extracted from the analysis of these two aspects would help promote the idea of regional game research, which is an approach that allows small and probably still unknown markets' voices to be heard. Game studies researchers would benefit from this research since they could realize that a change of the geographical referential system when researching video games could bring in new perspectives and further research directions.

\section{Space and the Idea of Regional Game Studies: Why We Have to See Video Games Beyond the Digital Space?}

Digital games and the gaming culture have become widespread global phenomena that gradually but steadily play a dominant role in everyday life regardless of participants' age (Hjorth and Chan 2009; Hjorth 2011). Game studies is the academic 
and interdisciplinary field of research that concentrates on studying video games, playing, and related phenomena (Egenfeldt-Nielsen et al. 2008; Mäyrä 2011). The rise of game studies seems to be connected with the development of games as a social force (e.g., Greitemeyer and Mügge 2014); however, it is not confined to any technology or medium. Several disciplines and methodologies have helped people understand the nature of video games, ranging from history and psychology to brain science, humanism, educational sciences, computer sciences, and recently cultural, critical, and media studies. This field has recently developed through video games research groups worldwide through explorative productions, books, courses, gatherings, blogs, and affiliations.

Since most of the previous game studies focused on the virtual space, the idea of the physical locality and its influence on the gaming culture, thus, has not been examined, at least at the theoretical level. As Massey (1991) stated, a global sense of space and place should be considered. The idea of going regional could be traced back to the road of heterogenization as an indispensable trend, which is also the core of cultural pluralism. Heterogenization maintains the idea that globalization guides people to greater diversity and the differentiation of cultures, ultimately leading to a greater understanding of different cultures and institutions (Tomlinson 1997). As each region has its own distinctive culture, analyzing video games developed in different areas may enable a better understanding of how video games' form and function are influenced by the cultural context in which they are situated in.

In terms of regional scholarship, Wolf (2015) commented that most of the books were written for North American readers in the early years of video games research. This was because the USA has a monopoly over the video games consumer market at first. When the Japanese game industry made its notable debut in the $1970 \mathrm{~s}$, a new chapter of this East Asian country was added, followed by several small sections that tell stories about Europe. Although Schleiner (2020) thought that the idea of having transnational research on video games could be traced back to this time with a trans-border comparison between the USA and Japan, studies on the transnational experience of gaming were still limited. A positive side of this matter was that countries in which games were imported have also formed their own distinctive gaming culture. The shortcoming was that the unique gaming culture was restricted to each nation due to the language differences and cultural barriers (Wolf 2015), which means that outside world did not have the chance to know and recognize one's trait of gaming culture besides the already-known names. With the rise of game studies in the 2000s and the increasing number of international gaming conferences, it became easier to analyze the more obscure regions' distinctive gaming culture because of collaboration on a global scale.

Schleiner (2020) argued that the East/West framework with the weight more inclining toward the West has existed for such a long time in game researchers' mind-set, caused by the fact that the history of video games was initiated by the USA - a typical Western representative. She noted that although this framework rightly recognizes national and regional differences and the existence of a transnational dialogue and cultural exchange on game innovation, it still has limits that a novel perspective better addresses globally, especially when looking back to the recent past, there was a transition that clearly changed the landscape. 
Speaking of area/regional studies, Schneider and Goto-Jones (2015) asserted that an erudite discussion on the concept of "area" must challenge our own sense of the location and consider others' locations. Spatially, these locations are attributed to specific geographical locales, but beyond that superficial understanding, an area or a region also showcases its distinctive ideological, social, historical, economic, and political facets. Naturally, when it comes to the concept of distinction, it does not mean that we have to fall into the trap of reproducing Orientalism or reheating the cold ashes of Cold War politics (Schneider and Goto-Jones 2015). Following this sense, a sensible approach that area studies should employ is the critical viewpoint from which researchers should understand that the geographically and culturally existing demarcation lines are not walls and fences isolating and dividing people. Instead, Schneider and Goto-Jones (2015) suggested that we need to look into the issue raised by such demarcations, what they mean to different people in different contexts, who benefits from asserting them, and what is happening on the other side of the line. Duara (2015) agreed with them on this point and added that we should go beyond the conservative idea of nationalism and move forward by considering the regional network's role.

By applying those ideas to game research, we could see that the transition from a meta-view consisting of the core North American and European markets to the subview of peripheral smaller markets should be the proper direction as within gaming culture and gaming scholarship, there exist unequal global relations and particular trajectories of development (Liboriussen and Martin 2016). Selecting a region, an area, or a country to focus on and calling the study a regional one does not mean that we naively fall into the trap of essentialism. Researchers tend to be biased when selecting their research objects to include the birthplace, the location that they have a deep emotional connection rather than an objective choice of study subjects motivated by pure epistemological thinking (Liboriussen and Martin 2016). It might mean that the researchers perceive those targeted regions that are unaffiliated with them as being less credible. Within the context of regional game studies, our emphasis on another region besides the traditional cores does not assume the default notion of eternal cores, leaving no chance for the "peripheries" to rise to an equivalent status of the cores. Instead, the shift to an equal research focus on both core and peripheral regions signifies the development of the game studies discipline. Therefore, the research shift benefits everyone, and East and Southeast Asia are worth studying.

Along with the rise of Japan, the revival and stable development of the USA, and the involvement of the Europe, video games have helped create a synthetic world where people live in a virtual environment, experiencing the blurry line between real-life and the gaming sphere since the $1990 \mathrm{~s}$ (Castronova 2005). However, East and Southeast Asia do not consist only of Japan since the gaming industry is built up by many countries. After World War II and especially after Asian countries gained independence following a long colonial rule, the demand for a rapid technology buildup, including informatics, has become a continual pursuit in order to help this continent progress to the status of the Western world and to facilitate their nationbuilding process. Thanks to this desire, the technological infrastructure in Asia has gradually but steadily developed to an advanced level, being capable of taking part in the race of the entertainment industry (Hjorth 2008). In a previous study, Hjorth 
(2007) also noted that since Asia-Pacific in general and East and Southeast Asia particularly are not a homogeneous entity, its diversity in terms of culture, political background, and technology development traits has made it an intriguing region for game research as the region would provide new insights to the global gaming industry.

\section{Research Method}

In order to converge on the sense that there has been indeed the emergence of East and Southeast Asia in the field of video gaming, this paper has employed the documentary review method with much of the data reviewed and analyzed that were extracted from books and documents that have examined the situation of the mentioned regions. The emphasis has been put on the academic voice of scholars whose research interest is the role of East and Southeast Asia in the age of digital technologies, its position as the other half of the juxtaposition Eastern-Western, and its intra-regional and transnational dynamics of which video games do not stand on the marginal side. Published works focusing on the Asia Pacific, especially East and Southeast Asia, in the last ten years were retrieved thanks to the search engines provided by libraries of the National University of Singapore and the University of Zurich.

This study also serves as a reflective view after consulting reports released by either Niko Partners or Newzoo. These reports are provided free of charge on a subscription basis. Niko Partners, a Silicon Valley-based company with offices in Shanghai, Bangkok, Jakarta, and London, is a market research and consulting firm covering the Asia games market and its consumers. Founded in 2002, Niko Partners provides qualitative and quantitative data collection and analysis, market models, forecasts, and strategic advisory services to deliver the intelligence and answers necessary to understand the regions better. Niko's services include syndicated and custom research studies and consulting services, including focus groups, partnership selection, and market opportunity analysis. Similar to Niko Partners, but covering a larger scale, Newzoo is a company that was founded in 2007, specializing in games, eSports, and mobile intelligence with offices in Amsterdam, Shanghai, and San Francisco. Their main tasks are to provide clients (mainly investors, companies, and researchers) with a mix of market trends, financial analysis, revenue projections, consumer insights, data modelling solutions, and predictive analytics services across all continents, screens, and business models. Besides, Newzoo has also built an analytics platform on which in-depth game, genre, country, and demographic profiles with real-time engagement and market-sizing data are available. Thanks to myriads of reports, infographics, and analyses regularly released by these two companies, game researchers could detect the changing nature of the industry and the gaming culture, as well as new nuances added to everyday (digital) life.

A qualitative approach serves as the primary research approach for this study. The thematic analysis was selected to help orient the collection and analysis of the data retrieved from sources mentioned above (Clarke et al., 2015). The author mainly focuses on writings that mention and analyze the gaming industry's development, 
the status of the market, and various facets of the targeted regions' gaming culture. The information gathered was categorized according to Braun and Clarke's six phases of thematic analysis to identify the common theme (Braun and Clarke 2006). These phases include reading and re-reading the data, generating patterns, combining patterns into overarching themes, reviewing themes, defining name themes, and producing the final report.

\section{Why East and Southeast Asia Matter?}

Schneider and Goto-Jones (2014) recognized that the technologically-savvy societies of Asia have been incredibly vibrant. They cited several reasons to illustrate, and all of these reasons come from countries that belong to the surveyed regions: China and South Korea. As the rising force in the physical markets and the digital space, China is home to numerous social media platforms like Tencent QQ or Sina Weibo - those that have successfully taken the place of foreign social networking sites thanks to the protectorate policy of the Chinese government. In South Korea, although Facebook, Instagram, and Twitter have been seizing the thrones of most popular social networking sites, it does not mean that this country does not have other services like KakaoStory, Band, Cyworld, or me2day serving as other counterpoises. These local products have provided Korean customers with a digital venue where the Korean Wave is still nurtured, strongly growing, and spreading. Schneider and Goto-Jones (2014) concluded that since the same plot could also be retrieved from other places in East and Southeast Asia where digital media with video games as an inherent component are increasingly allowing users to coordinate their actions, the emphasis put on these regions when conducting regional research is not futile.

There are several reasons to explain the emergence of Asian digital gaming, including the size of the market, the new center of production, youth culture, and the government's controlling scheme (Jin and Schneider 2016). Although these reasons could be considered valid to some extents, the fact that they were discussed cursorily and did not include specific examples might devalue their significance, especially when these reasons might sound in the case of East and Southeast Asia but not necessarily be right in the situation of other Asian regions. Thus, these reasons should be more deeply analyzed to clarify why the surveyed regions should be taken into account.

\subsection{East and Southeast Asia: the Most Lucrative Markets}

Asia is now considered the most prominent market globally in terms of total revenue and the number of players, of which East and Southeast Asia are the leading regions. In the recent report on the global gaming industry conducted by Newzoo (2018b), $52 \%$ of the whole world's total revenue must be credited to Asia-Pacific, while Europe is the runner-up, leaving the third rank to the USA. Thanks to the expansion of the mobile device market in East Asia and Southeast Asia, the growing trend recorded from mobile gaming and online gaming starting from the beginning of 
the 2010s would be continuous, stabilizing the advancing impetus of the revenue in upcoming years. According to the most recently published report by Niko Partners (2018), Southeast Asia is the world's fastest-growing region for PC online games revenue. The region is also home to the most viral market for eSports, entailing the presence of professional teams, tournaments, and investments, which are all hot and show no sign of slowing down. Both Newzoo (2015) and Niko Partners (2018) commented that improvements in internet infrastructure and disposable income, coupled with demand for eSports games, tournaments, streaming, and more, have set the stage for continued growth in the next decade. As predicted by Niko Partners (2018), the combined PC online and mobile games revenue is projected to grow from $\$ 4.4$ billion in 2018 to $\$ 7.5$ billion in 2022, while the number of gamers in Southeast Asia is expected to grow from 244 million in 2018 to 309 million in 2022. Besides, both regions' growth is guaranteed to be boosted thanks to the generous investment by multinational companies and country governments (Newzoo 2019b).

In terms of penetration, the possibility of infiltrating Southeast Asian countries is higher than its main counterpart-China, making it a better option to invest. The most prominent feature that allows this entrance is that all countries in the region have been familiar with the English language as the lingua franca of international business and popular culture. According to Crystal (2003), the Singapore's census (2010) as well as Low and Hashim (2012), the proportion of people who could speak English in the top 6 countries (in terms of revenue gained from video games) in Southeast Asia makes up an average of 30\%, ranging from $10 \%$ in Vietnam to more than $80 \%$ in Singapore. English is the official language in Singapore and the Philippines, while in Malaysia, this language is the second in command used in their everyday life. The rest of the region widely uses English in their business, especially in tourism and hospitality. China's situation is not as bright as Southeast Asia since only $1 \%$ of the Chinese population is capable of using English autonomously (Smith, 2017). Furthermore, in investors' eyes, Southeast Asia's activeness well resembles the same situation in the West since this region has the same preference for the international social network. Meanwhile, China's protectionism that helps promote domestic products has limited access to even some most popular search engines like Google or Bing, not to mention popular social networks such as Facebook or Twitter.

East and Southeast Asia are also the most dynamic regions in producing games (Jin and Scheneider 2016). As mentioned above, in terms of consumption habits, neither arcade games nor console games are the top choice of players in Asia; Japan, however, is one of the biggest console manufacturers who owns some very notable brand names, including Nintendo and Sony, although arcade centers still play an essential role in everyday life of the Japanese until today. According to Sambe (2009), as of 2009, 6 billion out of 20 billion in Japan's revenue come from arcade games while home consoles and mobile games' revenue in sum capped the year with 5.5 billion. After the economic recession in 2008, the revenue of Japan's gaming industry went down. The growth of mobile phone use has weakened arcade games' popularity, but Japan could not obliterate this format. Meanwhile, the online game production is dominated by South Korea and now China, which has recently become the most significant controller of the market share, not to mention Taiwan, which 
also had a long experience in processing games (Cao and Downing 2008). Both regions are also famous for their mobile communication technology, which rapidly expanded, setting the foundation for mobile gaming and instant messaging platforms that also serve as the system for in-app mobile games. As arcade games and consoles seem to be more prevalent in Europe and the USA, mobile and online gaming should also be the new focus of gaming scholarship in Asia (Newzoo 2019a). For example, Newzoo (2019b) revealed that Thailand is currently the number one market in Southeast Asia. The rise of smartphones in the late 2000s allowed the Thai market to prosper, with $31 \%$ of the revenue from the mobile section. Newzoo (2014) provided that Thai gamers spend more than \$27/person annually, with half of the players agree to pay, especially when it comes to racing games, the most favorite choice of genre.

The number of smartphone users in Asia is significant, where five out of the top fifteen countries with the most smartphone users include China, Japan, South Korea, India, and Indonesia (Newzoo 2018a). Except for India, the other top positions belong to East and Southeast Asian countries. It is worth noting that most of the recognizable brands who manufacture smartphones are now located in the examined regions with Samsung, LG, Huawei, Xiaomi, Oppo, Vivo, Meizu, Sony, Asus, and HTC, to name but a few, while the West only contributes some names such as Apple, Blackberry, Nokia, and Motorola. Although Apple is dominant thanks to their creativity and the Halo effect from their past products, other Western manufacturers are behind Asian companies. Furthermore, East and Southeast Asia are also the origins of many well-known messaging apps used by millions of users, including Viber, Line, KakaoTalk, WeChat, and Zalo. These apps' most striking feature is that they offer a complete eco-system presenting a wide range of add-ons, including mobile games. The mutual relationship between messaging function and gaming could be traced back to the legacy Yahoo Messenger, which provided platforms for users to play board games and draw doodles in a separate window while chatting; thus, it is not a new concept. What should be considered the breakthrough is that these apps make users feel that they get benefits when playing games by exclusively offering a lot of add-ons (sticker, emoticon that could be used when chatting) when installing or playing games. These stickers or smileys will be updated with meticulous design, making people eager to download. Both regions know how to engage the youth culture as the consumption tendency is well-documented in mobile market reports (Newzoo 2018a).

The glare of the publicity now concentrates upon the mobile gaming in Southeast Asia with an established Western games distribution channel and a troop of regional publishers who are on the cutting edge of not stopping at outsourcing but moving on to design and release games on their own. According to Newzoo (2015) and Niko Partners (2018), the mobile growth in the region from 2014 to 2017 surpasses 180\%, with half of the dominant games on mobile phones are Western titles such as Clash of the Clans, Hay Day, Boom Beach, Clash Royale or Candy Crush Saga which came from companies in the West like Supercell of King. Nonetheless, regional publishers have tried to make their names unforgettable by programming and releasing on Google Play and App Store their own titles. Some notable names include the phenomenal Flappy Bird of Nguyen Tien Dong or Infinite Shooting produced 
by Onesoft of Vietnam, or the hit of 2010 in the Puzzle game genre Unblock Me of Kiragames - a Thailand-based company that earned more than 25 million downloads within one year. These endeavours have proved that Southeast Asia has the full capability to build up their own game industry equipped with the ability of selfproducing instead of merely leaning on processing or localizing, although we have to confirm that outsourcing and conducting localization process are ongoing in revenue generation.

\subsection{East and Southeast Asia: Various Patterns of Gaming Culture}

As noted by Chan $(2006,2009)$, although the transnationalization process has taken place for years between countries, the idea of having the individual pattern that reflects the concept of nationalism is available, helping us imagine how the notion of national identity should look like in the wake of the digital era. Given East and Southeast Asia's ongoing success, they offer a good example that illustrated the Asia phenomenon in terms of economic triumph, consumption habits, and youth culture. For instance, China seems to be the newcomer who is rebranding its image as a country that has the ability to compete instead of merely using the copy-and-replicate tactics that helped them attract attention in the past and the present. Meanwhile, the gaming industry in Japan and South Korea have moved in two opposite directions. Individualism and portable devices in Japan contribute to the birth of the gaming culture in Japan. Since the $80 \mathrm{~s}$ with the release of the Game and Watch series by Nintendo to Game Boy series, Sony PSP series, and Nintendo DS series in the $1990 \mathrm{~s}$ and 2000s, the striking feature of having personal devices to play games in Japan has been illustrated clearly. Therefore, Japan's "individualistic" gaming culture is differentiated from South Korea's "communal" gaming culture.

\subsubsection{Individualism}

As Kogawa (1984) mentioned, the concept of individualism in gaming did not start with video games per se but with another device released by Sony in the 1970 s of the twentieth century: the Walkman. As music's taste is subjective, owning a portable music device marked individualism's birth and the personal space in Japan. Ito et al. (2006) and Manh Tuan (2016) have written some detailed analyses of mobile phone use in Japan since its first release in 1979, according to which the excessive use and reliance on mobile phones in Japan have amalgamated into a particular cultural phenomenon, which is called keitai or garakei. While keitai means portable, the prefix gara- refers to the island Galapagos as the authors asserted that the nationalistic nature of mobile phone use in Japan could be observed through the way it has been displayed, which is an explicit example of localism. The reason given is that the rapid technological development in Japan has created its own eco-system that only matches Japanese people's demand, who have been familiar with that kind of developing velocity. Besides, as national pride is one of the inherent characteristics valued by Japanese people, having a particular type of cell phone network is understandable. Fujimoto 
(2005) even named several other cultural phenomena that arise from the idea of using pager and the transition from males to young female users in Japan. The Japanese have embedded the concept of cuteness and personalization in mobile phone design and use, according to the aesthetics, perfection, and effectiveness concepts in Japanese people's philosophy. These elements helped create an aesthetic feeling of isolation in designing and using mobile phone systems, which somehow make people think of the isle Galapagos, a lonely island in the ocean that has grown its own original eco-system. However, the "lonely island" concept is also a double-edged sword, which led to the decline and replacement of Sony's Walkman by Apple's iPod in the 2000s. Sony created its own unit for distributing music with a strong copyright-protection level that no other company ever had, while Apple offered a more user-friendly software (iTunes) that still allows people to buy songs, and a mechanism guaranteeing that copying music into the iPod device is not a difficult task.

Manh Tuan (2016) also described that this seemingly peculiar keitai culture features a network that does not support the protocols of Global System for Mobile communications (GSM), which means foreign phones cannot be used in this country; and clamshell-shaped feature phones are the dominant type of design although, in the rest of the world, smartphones with flat design have been the selection for years.

There are three reasons why people have that kind of consumption habit (Tuan 2016). First, it is worth noting that Japanese people have used the Internet on phones much sooner than other users in the world. On February 22, 1999, when Docomo, one of the three biggest phone service providers in Japan, released i-mode, which is the phone with Internet connecting function, the rest of the globe only knows three basic tasks when using a cellular phone: call, receive a call, and text. The concept of innovation and technological advancement in Japan and how Japan's technology innovation system works (MacDowall 1984) have enabled it to surpass other countries. In particular, the next generation of cell phones in Japan is equipped with high-end technology capable of displacing other so-called flagship smartphones. Besides, Japanese people do not want to change their habits since they are familiar with clamshell feature phones; therefore, transiting to using smartphones with a flat and uni-body design is foreign to them. These two factors contribute to a situation where the Japanese use clamshell phones with multifunction embedded inside a small piece used to call and watch TV. Secondly, the economic crisis in Asia in general and in Japan, in particular, has made people rethink their spending power and spending habits. Manh Tuan (2016) noted that Japan is known for its expensive living expenses, entailing the steep price of a smartphone while a feature phone costs cheaper but still offers a wide array of functions. Manufacturers in Japan have also recognized this factual matter, which results in their release of many feature phone models that allow users to interact using the touchscreen or rotate the display monitor to watch television or play games. On the one hand, these functions help confirm the existence of feature phones; on the other hand, it also helps maintain the concept of individualism at an affordable level. Thirdly, the aging population in Japan is a common social phenomenon. Older people usually do not want to change their habit of using hi-tech devices as they prefer gadgets of simplicity over phones 
with a complicated structure and a virtual keyboard that drives them uncomfortable (as they make mistakes when typing all the time).

\subsubsection{Collectivism}

Gamers in the analyzed regions do not think that that video game is merely a pastime as they do take it seriously. Their activities range from investing large amounts of money in purchasing items and upgrading characters, hiring professionals to help them maintain or level up their rank, trading in platforms, and even becoming eSports participants who spend time training and competing for valuable prizes. Jin $(2010,2011)$ asserted that online gaming in South Korea has become a popular pastime of youths since the birth of Blizzard's StarCraft in 1998. Television shows now air competitions, and gaming is seen as a profession. Even national teams compete in tournaments that were promoted by South Korea, and this phenomenon has spread out to the whole East and Southeast Asian regions where youngsters live inside training camps sponsored by individuals or organizations, and playing games is the one and only part of the assignment (Kshetri 2009). Grubb (2015) highlighted that $61 \%$ of the revenue gained from the eSports business comes from Asia, where players immerse themselves in playing Dota 2, League of Legends, Age of Empire, and the newest games, PlayerUnknown's Battlegrounds, and Garena Free Fire.

Video gaming also plays a crucial social factor. It has helped build up a bonded virtual community in the mentioned regions where people create a social network by not playing alone but playing as a member of guilds, clans, or groups. Stewart and Choi (2003) noted that when joining an in-game event, Korean players would seize a whole PC-bang (Internet café in Korea) for their clan, completing the event together, although maybe five minutes ago, they were still strangers in real life. Previously, Herz (2002) observed the very same scene in the game Lineage:

What makes Lineage a distinctly Korean experience is that when players assemble to take down a castle, they do so in person, commandeering a local PC bang for as long as it takes. In the middle of a battle, these people aren't just text-chatting. They're yelling across the room. Platoons sit at adjacent computers, coordinating among themselves and taking orders from the Blood Pledge leader.

Stewart and Choi (2003), as well as Huhh (2008), shared a consensus with Hjorth (2011) on the point that the development of gaming in Korea has been associated with the notion of bang, which has primarily been contributing to collectivism recorded in East and Southeast Asia since this bang model has infiltrated and influenced other countries like Vietnam, Thailand, or Indonesia where the net of Internet cafés was widely established. Actually, the concept of bang refers to a public space where people who share the same interest gather and do things together (Stewart and Choi 2003). The bang system includes video-bang, where people watch video clips, DVD-bang where people rent DVD and watch together, manhwa-bang where people read comics, nore-bang where people sing together (which is similar to a KTV), and then PC-bang- the place where people use the Internet and play online games. Huhh (2008) and Jin (2010) agreed that although the high-speed connectivity, 
hi-end computers, and low access fees of around $\$ 1.5$ per hour are crucial reasons that attract Koreans to go to PC-bangs, the social bond generated from this activity is the primary factor that leads to the popularity of more than 20 thousand PC-bangs in the whole country The idea of socialization in online gaming in Korea is therefore formed by the popularity of PC-bangs. Naturally, this phenomenon cannot be a result of a short-term endeavor. Mun (2001) argued that the expansion of the Internet and computer use in South Korea is a ground-breaking effort by the government to transform South Korea into a leader in the computing era of the twenty-first century. According to Stewart and Choi (2003), the government promoted competition between different Internet service providers, encouraging them to build up a network foundation that connects the whole nation.

Although the government reserved the project for the public sector, the private sector saw the potential in this plan and immediately jumped on the bandwagon, resulting in the establishment of PC-bangs. The synergy between the high-performance technology pursuits of the state and the benefit accumulation desire of the private companies initiated the nationwide Internet connectivity, although the distribution imbalance and the gap between the corporations and localities were well recorded. Logues and Jung (2001) indicated that the divide is still present regardless of the Korean government's effort. However, the divide here does not refer to the number of access points or the hi-speed connection as the state has justified that they did know how to solve these requests: The number of PC bangs is increasing day by day, and the Internet's connection speed in Korea is the fastest in the world (Akamai 2015). The most critical issue that Logues and Jung (2001) pointed out is the gap between old and young Koreans who do not have the same competency level in using the Internet and computer. Additionally, they noted that the Koreans do not possess proficient computer skills that correspond to the time spent on the device since most of the time, they use that time to chat and play online games in PCbangs rather than to use the Internet and computer for more sophisticated tasks. The socialization in online gaming is thus beneficial only in creating the human bond at the interpersonal level, while at the individual level, the Koreans do not advance in terms of self-improvement.

Besides, Chosun (2006) also highlighted an underground risk that might damage PC-bang's reputation as a place of gathering and socializing. In particular, the presence of Sea Story, which is a coin-operated machine, has created huge success in terms of revenue. Several PC bangs have been transformed into illegal gambling spots in order to capitalize on the financial benefits provided by Sea Story. Although gaining profits is the main reason to open and operate a PC-bang, its original function does not include gambling or any type of illegal activity. Huhh (2008) thus proposed that the scandal or transformation of Sea Story should be taken into account seriously.

As mentioned in the paragraph above, computers' popularity opened up opportunities for various Web shows and programs. Since the introduction of StarCraft in 1998, online gaming in South Korea has not only been confined to the space of a PC-bang, but it is also about eSports, a competitive type of play that allows both amateurs and professionals to participate in matches that are televised and reviewed regularly. Instead of focusing on arcades, console games, or offline 
PC games, South Korea has made a wise choice of selecting online games as their ideal domain to invest and develop. This choice was made based on South Korea's available network infrastructure and South Korean gamers' personal preferences. These two factors helped increase South Korea's online gaming market share. According to Jin and Chee (2009), it is indisputable that South Korea reigns supreme when $32 \%$ of the global market share is credited to South Korea, although China has been gradually taking over the top spot.

Lee et al. (2002) asserted that the difference between Japan and South Korea could be traced back to their dissimilar systems of cultural value, which were displayed clearly during the adoption and deployment of Internet services. One of the Internet features focuses on the idea of mass sharing ranging from music to any kind of digital content, which has molded the Internet into a consumption format that relies on the existence of the peers and economies of scale (Lee 2001). Computers, therefore, have become a tool that strengthens social bonds as people build virtual connections in the same way in which they create, develop, and maintain physical relations. The results from this tendency were the production of shows and programs aired exclusively online, blogs incorporating the format of video clips or video game's live streaming, to name but a few. That is likely the case in South Korea. By contrast, Ishii (2004) gave us a different perspective of Japan where people now, especially the youth who have to endure workload pressure and educational expectations, tend to orient themselves to the concept of individualism (Miyanaga 1993) in using Internet services and handhelds. According to Ishii (2004), Japanese who have the habit of using computers show the trend of isolation rather than Japanese who use mobile phones, and thus smartphones serve as the social link for Japanese youths together with messaging apps, forums, blogs, vlogs, and games. Nonetheless, the increase in individualism also leads to a darker fact. Teo et al. (2010), Teo (2013), and Teo et al. (2014) have done a chain of research on the topic of Japanese youth who cut familial ties to seek out extreme isolation, almost completely withdrawing from reality. In Japanese, those who choose to confine themselves to an isolated lifestyle are called hikikomori, which means pulling inward; the only connection they maintain with society seems to be conducted via handhelds. The commonness of mobile phones entails several digital products, including mobile phone novels and mobile games.

Additionally, Hjorth (2011) commented that the governmental policy in Korea focuses on developing the Internet structure, such as its connection speed and spread, with which the PC-bang culture has arisen as a direct result. Korean's virtual and physical identities are more closely related to each other (Hjorth 2011). Their use of the Internet requires the registration and the revelation of personal identity, and the Koreans consider PC-bang as a gray area between home and other places (Chee 2005). As the Koreans must declare their identity, they treat the Internet as another reality dimension built digitally rather than an alternative environment. Meanwhile, affordable access to the Internet in Japan only came with the emergence of mobile phones and Internet services integrated into cell phones in the late $1990 \mathrm{~s}$. In the situation of Japan, anonymity is still guaranteed in using digital services, and thus, their personal space is preserved. 
Although there were times when foreign mobiles could not be used in Japan, this is no longer the case today with smartphones that support hi-speed $3 \mathrm{G}$ and $4 \mathrm{G}$ technology being widely used, not to mention that the $5 \mathrm{G}$ telecommunications services are going to be available soon. However, the attachment to smartphones and handhelds that originated in the past has brought some issues to video gaming development in Japan, which is now unbalanced between different categories of games. Kyodo (2020), Nippon (2019), and Suk (2018) all commented that while eSports has been establishing itself as a way for gamers around the world in general and in Asia particularly to make a living and even build their fame, Japan has lagged far behind in the trend. The reason why eSports had trouble taking root in the Japanese soil is mostly credited to two elements. First, the video game market remains dominated by single-player titles designed for smartphones and the gaming consoles of wellknown companies such as Nintendo and Sony, which is understandable since the habit of handheld usage has been a part of everyday life in Japan. Second, Japan's belated participation has been facing the hindrance caused by legal barriers, including a law that does not allow game-makers to hold competitions offering substantial prize money since the government has been afraid that these tournaments could be used as a method to promote their products. Suk (2018) commented that Japan is the country in the world to have this kind of regulation; and game companies have to find ways to skirt this troublesome law by negotiating with the Consumer Affairs Agency, pledging that the contestants are professional competitors with licenses issued by the Japan eSports Union (JESU). These obstacles have brought some ramifications to eSports' development in Japan, including the lack of expertise in organizing large tournaments and dealing with intellectual property rights and other legal issues related to game developers (Kyodo 2020). Being aware of this current stagnant situation, the Japanese government is planning on spending big on eSports, starting with the formation of JESU in 2018. Kyodo (2020) informed that the Ministry of Economy, Trade, and Industry would work with companies and legal experts to draw up guidelines for promoting Japan's eSports industry. The Japanese government will also introduce an ambitious plan to expand Japan's eSports industry with the private sector to help revitalize regional economies and increase social participation by people with disabilities, aiming to a sum of $¥ 285$ billion ( $\$ 2.6$ billion) in economic benefits a year by 2025 .

\subsection{East and Southeast Asia: the States' Concern}

The last reason making the regions salient is the intervention of the regions' governments and related administrative bodies to manage and control the industry. Noticing that video games could bring up a chain of issues including harmful contents ranging from nudity, profanity, hostility, to terrorism and anti-communism, game addiction, online gambling, and illegal distribution, the governments in East and Southeast Asia have shown deep concern about the impact that video games can make (Lent and Fitzsimmons 2013). The video gaming industry has generated a considerable amount of revenue for the economy, entailing a generous tax payment, and countries such as China and Vietnam have promulgated numerous policies to 
ensure that video gaming can operate freely within boundaries. These boundaries, also known as legal frameworks, have been issued to protect the countries' ideology, prevent addiction, or even use games as a propaganda tool. The most frequent reason that the state uses when issuing policies is addiction prevention. Many players suffering from addiction and related crimes have been increasing, explaining why distributors and gamers try to show a cooperative attitude towards these policies. Nonetheless, despite the semblance of adherence to these legal frameworks, there is an underlying dispute as gaming companies feel that they are restrained and lose benefits while gamers perceive that they are always under scrutiny.

\subsubsection{Neo-Techno-Nationalism as the Gaming Culture of China}

The case of online gaming in China is a good example to help understand the government's role. Statista (2018) predicted that the Chinese online games market could generate more than $¥ 416.9$ billion in 2022 . Ewing (2007) stated that in $2006,90 \%$ of Chinese gamers play online games with role-playing games as the dominant genre. Chinese national spirit has been embedded in China's online games to promote Chinese political discourse by leveraging the online game's popularity. Liu (2008) mentioned that the Chinese youths consider online gaming a platform to show their national attachment, and they can exercise control over the gaming activity because they understand that gaming addiction is common. Finally, the number of camps that train professional players to compete is also increasing. The idea of nationalism does not stop there as the government has collaborated with companies to design and export games to other Asian and Western countries, implying that online games are useful to introduce Chinese culture through wuxia-themed and history-based games (Kshetri 2009). While other platforms such as consoles and PC games are not significant, the increasing turnover trend of online games has a more stabilizing effect as Chinese companies usually sell their games cheaper than South Korean or USA products, assuring a huge source of clients from Vietnam. The number of players in China has also gained an increase of 57 million since 2006 to an impressive number of 177 million (Statista 2018). This continuous growth helps China earn the position as one of the three pillars of East Asia.

Jiang and Fung (2019) conducted an extensive analysis of the game development agenda in China, with the state lying at its heart, playing the role of the main engine. According to these two authors, the development of China's online game industry is not driven by capitalist forces but ignited by state power. The state's involvement in both governing and encouraging the development of gaming in China has been explained by the concept of neo-techno-nationalism, which is a term coined by Yamada (2000). Shim and Shin (2016), as well as Higgins (2015), elucidated that the state now agrees to step out of its comfort yet closed zone and starts bonding with the private sector, forming a new mutual public-private partnership and being more open-minded to opportunities brought by foreign agencies, as well as considering international legislation and policy coordination. Suttmeier and Yao (2008) performed a comparison and pointed out that unlike the idea of techno-nationalism that purely promotes national interests and does not tolerate foreign involvement, which is the model that China applied during Mao's era; or the concept of 
techno-globalism that echoes to the idea of globalization, which was made possible thanks to the Reform initiated by Deng Xiaoping in the 1970 s, the neo-technonationalism pursued by China now is a versatile fusion, serving as the response to the peer pressure brought by foreign countries after China joining the WTO in 2001. As a crucial part of the creative industries, gaming has also been under this ideology's influence. Jiang and Fung (2019) pointed out that locally, the state has tried to ameliorate the legal system and elaborate domestic conditions for gaming companies in China, with which innovative ideas are well nurtured and given room to flourish; while internationally, the government has actively engaged in developing new technologies and promoting exports, as well as building the national image in order to facilitate multilateral trading activities in which video games also play a crucial role as one engine actuating the soft power expansion plan. Thanks to this direction, Chinese mobile games have recently accounted for 19 of the top 100 highest-grossing games in the USA, raking in a combined \$487 million in revenue and underlining the drive by some developers overseas. The total earnings gained by these 19 titles accounted for $16.3 \%$ of the revenue generated by the top 100 games (Ye 2020). This strong showing for Chinese games in the overseas market might be explained by the global boom for online entertainment amid the COVID-19 pandemic that forces people to search for alternatives to replace real-life activities during the time of lockdowns and social distancing, but at the same time, it is also evidence to prove the new ideology recruited by the Chinese government. Nonetheless, as aforementioned, this new mixed model still emphasizes the central role of nationalism, which caused increased saturation and more stringent regulation, pushing Chinese companies to turn to overseas markets.

Storz et al. (2015), Schneider (2018), as well as Jiang and Fung (2019), indicated that although the government of China has endorsed online game industries as a driving force that helps foster economic development, bring economic benefits, and create job opportunities, it is undeniable that the state wants to open a window for determining how the creative industries in general and gaming, in particular, can be used to strengthen the central role of the governing bodies, empower the national image, and promote positive social connections among the youth. Thus, the regulatory landscape is always the highest barrier to China's video games market. The labyrinth of strict content regulations and the diverse range of regulatory bodies with overlapping duties have made it difficult for gaming companies in China, putting them into a nearly dead-end of finding ways to comply with the multi-level legal framework coordinated by various regimes without facing conflicts of interests (Koty (2020). The situation has become more extreme, starting in 2018 when the state decided to put the whole market on hiatus for ten months in order to use that time for recalibrating the legal framework. Niko Partners (2020a) released a detailed report on the dramatic overhaul to the regulation and licensing of digital games in China, showcasing that after this freezing time, the policymakers introduced some reforms that enormously altered the regulatory framework. Jiang and Fung (2019) shed light on this matter by pointing out that online games in China are closely related to controversial vices comprising Internet addiction, (cyber) violence, and pornography. Thus, the strict measures imposed are largely understood as a doublebarrelled effort to protect the domestic market and national unity. 
The concept of digital nationalism has effectively infiltrated the realm of eSports culture in China thanks to non-stop endeavours of the state. Szablewicz (2016, 2020) addressed the proliferation of images and appearances in live eSports events in China and concluded that these events, along with the active participation of the Chinese youth, are less about spectatorship and not merely about fandom and playing per se. The combination of these elements has created a spectacle that reasonably represents a meticulously crafted vision of Chinese politics and consumer culture. In this situation, people might not clearly detect the state's involvement, but the masking contradictory and the ambitious discourse narrated by the government about their role in the technological sphere is there to be recognized. The selection of location that hints at a techno-savvy society and the potential for further development, the governmental sponsorship, the presence of high-ranking officers, the nationalistic content of their speech that promote the concept of ideal citizens, the streaming of these events on channels that serve as the mouthpiece of the state, all of these factors pander to the fact that the gaming culture in China is not disengaged from the coordination of the state.

\subsubsection{Supportive Governance: the Aspiration of Southeast Asia}

Southeast Asian countries have a regulatory landscape that is more relaxed than China. Indonesia- the largest country in Southeast Asia, could be cited as an example. Indonesia has the largest population, ranked number four globally with more than 250 million people, 130 million of whom live in Java, where the infrastructure and the living conditions are better than the other islands (Rakhmani and Darmawan 2015). According to the CIA (2014), 51\% of Indonesians live in urban areas, with 10 million live in the capital Jakarta where people feel more comfortable spending money for amusement in comparison with other rural areas or under-developed regions in the country. Newzoo (2015) commented that the most impressive strength found in the demographics of Indonesia is the young population and corresponding large workforce, which is considered the main source of consumers and the primary driver for the growth of the online community that made up $20 \%$ of the whole nation's population.

Mobile games were the recent tendency in Indonesia but already promised a steady development in the future. Newzoo (2015) observed and commented that $49 \%$ of mobile gamers in Indonesia do not hesitate to spend money on items or ingame packages with an annual spend of more than $\$ 9$ per person. The most selected mobile game genre in Indonesia is strategy games, which also attract gamers to spend the most, with $41 \%$ of players being ready to open their wallets. This high spending power is backed by the rise of local game developers who tend to choose mobile games to focus on rather than PC games as the budget for one mobile game title is only around $\$ 1000$, while ten times of that amount are not enough to develop a PC online game.

Recognizing the potential of video gaming, the government of Indonesia seems to be most interested and involved in gaming-related events, with high-level officials, including the Chief of Staff to the President, Minister of Communication and Informatics, and the head of the Creative Economy Agency recorded to attend gaming 
events and to state their support to the development of gaming and eSports in Indonesia (Niko Partners 2020b). According to the recently released analytics from Niko Partners (2020b), this island nation's state has also concretized its serious interests by showing notable supportive moves. For example, gaming and app development are now considered top creative industries that should be fully supported by the Ministry of Tourism and Creative Economy. In terms of public events, the Indonesian state even tried to lobby other Southeast Asian countries to agree on bringing eSports as an exhibition sport in Asian Games 2018 in Jakarta and pushing for eSports to be a medal sport in SEA Games 2019 in Manila. In terms of administration and policy promulgation, the Indonesian state included game development in Law No. 24/2019 on Creative Economy and updated the Sports System Law to include eSports. Thanks to these changes, local authorities can now provide incentives to the creative industries, including game developers. Besides, foreign investors could find more opportunities in this nation, as they can also directly cooperate with local governing agencies. Another act worth paying attention to is the integration of the Indonesian eSports association into the National Olympic Committee, which might suggest that Indonesia's ambition regarding video gaming and digital sports is reaching the global level instead of merely isolating itself within the local boundaries.

Singapore is another example that helps illustrate the aspiration and the involvement of the state. As the most potent economic hub of Southeast Asia, being in the top five countries with the highest GDP per capita globally for many years, the spending power of Singaporean players is the runner-up to no other countries in the region. As a highly civilized and urbanized island country with a small population, the number of online users seized a proportion of $80 \%$, with more than $60 \%$ being vivid gamers who justified that spending $\$ 189$ per year for games has never been a big deal (Newzoo 2015).

Thanks to the English proficiency in the country, Wolf (2008) noted that this most receptive country of the West has the highest penetration of English games in Asia. In terms of PC games, the country's prosperity assisted its citizen in owning personal computers sooner than other countries in the region. Playing is only a part of the story as the Singaporean government's ambition uncovered that they had an interest in developing the game industry since 1995 (Chung 2015). Thanks to this goal, the state motivated game start-ups and signed agreements with Japanese companies to help Singapore build the infrastructure and train Singaporean experts. The government did not stop at the practicality level as they also fostered the game research by opening and sponsoring research labs. These transnational endeavors have brought an impossibly brighter reality as now Singapore has their own game studios that self-produce domestic games or outsource for big companies in Japan or the USA (Chung 2015). This country's strict law with a transnational tendency to recruit and expand business has encouraged foreign companies to invest and open official offices in Singapore, assuring that licensed products are sold. The severe penalties and high fines, if found guilty, are also useful tools that helped stabilize the market. Well-known companies like Ubisoft, Electronic Arts, or Lucasfilm, to name but a few, also set their branches in Singapore, believing that the legal framework, highly qualified laborers, and tech-savvy consumers in this country could guarantee 
the release of good products that match international standards (Chung 2015). As an interlinked industrial tycoon, Singapore confirms its leading position in producing in the future. The only issue lies in this country's unpopulous nature, which cannot promise a more surprising increase in terms of the number of gamers.

\section{Concluding Remarks}

Kim and Hodges (2010) proclaimed that although the twenty-first century might be the time of Asia's rise, it is hard to see how this continent is fragmented by its diversity. The different developmental traits of each Asian country in the Asian Pacific region are unique, and therefore, it is premature to conclude about the emergence of this area as a whole since national patterns have their own nuance.

This paper has explained why East and Southeast Asia could make its transition by focusing on the gaming industry and related studies on video games in this region. When we come back to the main question: Why game research should bother shifting the focus in the first place to these regions, we can now clearly see some reasons. The idea of looking at the juxtaposition of digital games and digital technologies and cultures from East and Southeast Asia is an insightful way to place the digital game at the center of area studies, which traditionally does not integrate video games in its research agenda. For game researchers, as Jin and Schneider (2016) proposed, this implies exploring not only the largest digital game market but also forming novel methods and theories to analyse digital games in Asia.

East and Southeast Asia are dynamic regions where games have attracted the attention of the outside world. Hjorth is right to argue $(2011,108)$ that examining the regions is not just about games and relevant issues only; regional game studies open up other perspectives to think about the geographical role in technology development, the activeness of a regional area, as well as techno-nationalism. Besides, techno-orientalism has embraced the conceptualization of the regions' emergence in technology in general and games in particular, as Japan, which is leading the technological development, has been seen as an "Other" compared to the Occident/Western counterparts. The Western dominance of the technology market has declined where first Japanese, then Korean, and now Chinese products have become more popular. The Otherness is now becoming a tale of "epicentre switching" to define who will be the future technological leader. Besides, she asserts that the regions also bring us two tendencies of playing games, which are striking features of three countries, Japan, South Korea, and China. Japan represents console individualism; South Korea introduces online gaming and online communities; and China shows the world the image of an emerging online gaming tycoon who has already surpassed Korea in terms of the number of gamers, the manufacturing of games as well as exporting power of online game titles.

Additionally, the seeds of digital gaming have also started to solidify some serious roots in Southeast Asia (Tech Collective 2019). As aforementioned, macroeconomic drivers of games growth in this region are the increase in the number of internet users, growth in disposable income across the region, and improvements in the internet infrastructure, not to mention the widespread 4G networks, which are soon 
to be updated to $5 \mathrm{G}$, promising a more stable and hi-speed connection for mobile devices. These, along with governments' support, lead to a prime growth environment in the region (Niko Partners 2018). In terms of consumption habits, we could witness that with the growth in income, we have seen a transition from low spend games to high spend games, and demand for competitive prized and eSports games that generally require higher spending than casual games. This shift might lay a new coat on the current trend of researching Southeast Asia's gaming market that was infamously known as the land of game piracy ( $\mathrm{Ng}$ 2006). Last but not least, eSports is the top driver for the growth of PC gaming in the region, according to which gamers are motivated by competition and completion (Tech Collective 2019). This type of indoor sport also helps build other industries, including tourism, which suggests other new research directions such as competition tourism.

Acknowledgements This research is funded by NUS Graduate Research Support Scheme granted by National University of Singapore, and by Swiss Government Excellence Scholarship granted by the Swiss Federal Commission. The author also wants to express the gratitude toward Dr. Toh Weimin (NTU-NIE) for his insights and assistance in proofreading this paper.

\section{Compliance with ethical standards}

Conflict of Interest The author declares that there is no conflict of interest.

\section{References}

Akamai. 2015. "Akamai's report on the State of the Internet." Accessed October 3, 2018. https://www. akamai.com/us/en/multimedia/documents/report/q3-2015-soti-connectivity-final.pdf.

Braun, V., and V. Clarke. 2006. Using thematic analysis in psychology. Qualitative Research in Psychology 3 (2): 77-101.

Cao, Y., and J.D.H. Downing. 2008. The realities of virtual play: Video games and their industry in China. Media, Culture and Society 30 (4): 515-529.

Castronova, E. 2005. Worlds to conquer online: multiplayer gaming comes of age synthetic worlds: the business and culture of online games. Chicago, IL: University of Chicago Press.

Chan, D. 2006. "Negotiating Intra-Asian Games Networks: On Cultural Proximity, East Asian Games Design, and Chinese Farmers." In special issue of Fibreculture, Gaming Networks 8, edited by C. Chesher, A. Crawford and J. Kücklich. Accessed November 8, 2018. http://journal.fbreculture.org/ issue8/index.html.

Chan, D. 2009. Beyond the "Great Firewall": The Case of In-game Protests in China. In Gaming Cultures and Place in Asia-Pacific, ed. L. Hjorth and D. Chan, 141-157. London: Routledge.

Chee, F. 2005. "Understanding Korean Experiences of Online Game Hype, Identity, and the Menace of the "Wang-tta"." DIGRA Conference, Changing Views-Worlds in Play, Canada.

Chosun. 2006. "'Sea Story' Case Puts Spotlight on Arcade Games." Accessed November 10, 2018. http:// english.chosun.com/site/data/html_dir/2006/08/21/2006082161022.html.

Chung, P.C. 2015. Singapore. In Video games around the world, ed. M.J.P. Wolf, 469-494. Cambridge, Massachusetts: MIT Press.

CIA. 2014. "The World Factbook." Accessed February 19, 2019. https://www.cia.gov/library/publicatio ns/the-world-factbook/geos/id.html

Clarke, V., V. Braun, and N. Hayfield. 2015. Thematic analysis. In Qualitative psychology: A practical guide to research methods, ed. J.A. Smith, 222-248. London: Sage.

Crystal, D. 2003. The Cambridge encyclopaedia of the English language (2nd edn). Cambridge: Cambridge University Press.

Duara, P. 2015. "The Agenda of Asian Studies and Digital Media in the Anthropocene." Asiascape: Digital Asia 2 (1-2): 11-19 
Egenfeldt-Nielsen, S., J.H. Smith, and S.P. Tosca. 2008. Understanding video games: the essential introduction. New York and London: Routledge.

Ewing, R.D. 2007. China's online video game wars. The China Business Review 34 (4): 45-49.

Finlayson, C. 2019. World Regional Geography. Quebec: Press Book.

Fujimoto, K. 2005. The Third-Stage Paradigm: Territory Machine from the Girls' Pager Revolution to Mobile Aesthetics. In Personal, Portable, Pedestrian: Mobile Phones in Japanese Life, ed. M. Ito, D. Okabe, and M. Matsuda, 77-102. Cambridge, Massachusetts: MIT Press.

Greitemeyer, T., and D.O. Mügge. 2014. Video Games do affect social outcomes - a meta-analytic review of the effects of violent and prosocial video game play. Personality and Social Psychology 40 (5): $578-589$.

Grubb, Jeff. 2015. "E-Sports Makes \$612M from its 134M Viewers Worldwide, SuperData Finds." Gamesbeat. Accessed November 20, 2018. http://venturebeat.com/2015/05/06/e-sports-makes -612m-from-its-134m-viewers-worldwide-superdata-finds/

Herz, J.C. 2002. "The Bandwidth Capital of the World." Wired 10.8. Accessed December 2, 2018. http:// www.wired.com/wired/archive/10.08/korea_pr.html

Higgins, V. 2015. Beyond neo-techno-nationalism: An introduction to China's emergent third way: Globalized adaptive ecology, emergent capabilities and policy instruments. In Alliance capitalism, innovation and the Chinese state: The global wireless sector, ed. V. Higgins, 115-145. New York, NY: Palgrave Macmillan.

Hjorth, L. 2007. The game of being mobile: one media history of gaming and mobile technologies in Asia-Pacific. Convergence 13 (4): 369-381.

Hjorth, L. 2008. Games@ Neo-Regionalism: Locating Gaming in the Asia-Pacific. Games and Culture 3 (1): $3-12$.

Hjorth, L., and D. Chan, eds. 2009. Gaming Cultures and place in Asia-Pacific. London: Routledge.

Hjorth, L. 2011. Games and Gaming: An Introduction to New Media. Oxford and New York: Berg.

Huhh, J. 2008. Culture and business of PC bangs in Korea. Games and Culture 3 (1): 26-37.

Ishii, K. 2004. Internet Use via Mobile Phone in Japan. Telecommunications Policy 28 (1): 43-58.

Itō, M., Okabe, D., and Matsuda, M. 2006. Personal, portable, pedestrian: Mobile phones in Japanese life. London; Cambridge, Mass: MIT Press

Jiang, Qiaolei, and Anthony Y. H. Fung. 2019. Games with a continuum: globalization, regionalization, and the nation-state in the development of china's online game industry. Games and Culture 14 (7-8): 801-824.

Jin, D.Y. 2010. Korea's Online Gaming Empire. Boston, MA: MIT Press.

Jin, D.Y. 2011. The digital Korean wave: Local online gaming goes global. Media International Australia 141 (1): 128-136.

Jin, D. Y., and Chee, F. 2009. "The Politics of Online Gaming." In Gaming Cultures and Place in AsiaPacific, edited by L. Hjorth and D. Chan, pp. 19-38, London: Routledge

Jin, D. Y. and F. Schneider. 2016. "The dynamics of digital play in Asia." Asiascape: Digital Asia, 3(12), 5-15

Kerr, A. 2006. The business and culture of digital games: Gamework and Gameplay. London: SAGE.

Kim, M., and H.J. Hodges. 2010. Is the 21st century an "Asian century"? Raising more reservations than hopes. Pacific Focus 25 (2): 161-180.

Kogawa, T. 1984. Beyond Electronic Individualism. Canadian Journal of Political and Social Theory 8 (3): 15-20.

Koty, A. C. 2020. "How to enter China's online gaming market.” Accessed April 18, 2020. https://www. china-briefing.com/news/entry-strategy-chinas-online-gaming-market-opportunities-license-compl iance/.

Kshetri, N. 2009. The evolution of the Chinese online gaming industry. Journal of Technology Management in China 4 (2): 158-179.

Kyodo. 2020. "Japan plans ambitious expansion of eSports to boost economy through 2025." Accessed May 2, 2020. https://www.japantimes.co.jp/news/2020/03/29/national/japan-expansion-esportseconomy-2025/\#.XrM8nqgzY2z.

Lee, C.S. 2001. An analytical framework for evaluating e-commerce business models and strategies. Internet Research 11 (4): 349-359.

Lee, Y., J. Lee, and H. Kim. 2002. A Cross-cultural Study on the Value Structure of Mobile Internet Usage: Comparison between Korea and Japan. Journal of Electronic Commerce Research 3 (4): $227-239$. 
Lent, J.A., and L. Fitzsimmons. 2013. Asian popular culture: New, hybrid, and alternate media. Lanham, Maryland: Lexington Books.

Liboriussen, B., Martin, P. 2016. "Regional Game Studies." Game Studies - The international journal of computer games research 16 (1). Accessed December 4, 2018. http://gamestudies.org/1601/articles/ liboriussen

Liu, M. 2008. Mao to now: China is thousands of years old but has been made anew in the last three decades, and my family with it. Newsweek 151 (1): 40.

Logues, W.E., and J. Jung. 2001. Exploring the digital divide: Internet connectedness and age. Communication Research 28: 536-562.

Low, E.L., and A. Hashim. 2012. English in Southeast Asia: Features, policy and language in use. Amsterdam, Philadelphia: John Benjamins Publishing Company.

MacDowall, J. 1984. The technology innovation system in Japan. Journal of Product Innovation Management 1 (3): 165-217.

Massey, D. 1991. "A global sense of place.” Marxism Today (June): 24-29

Mäyrä, F. 2011. An introduction to game studies: Games in culture. London: SAGE Publications.

Miyanaga, K. 1993. The Creative Edge: Emerging Individualism in Japan. New Brunswick, N.J.: Transaction Publishers.

Mun, S. H. 2001. Internet access of youth in South Korea: A case study of the PC room. Paper presented at the International Communication Association Conference, Washington, DC.

Newzoo. 2018a. "Top 50 Countries by smartphone users.” Accessed December 12, 2018. https://newzo o.com/insights/rankings/top-50-countries-by-smartphone-penetration-and-users/.

Newzoo. . 2014. Southeast Asia Games Market Report. USA: Newzoo.

Newzoo. . 2015. Southeast Asia Games Market: The World's Fastest Growing Region's Casual games sector report 2015. USA: Newzoo.

Newzoo. 2018b. Newzoo Global Games Market Report 2018. USA: Newzoo

Newzoo. 2019a. Newzoo Global Mobile Market Report 2019. USA: Newzoo

Newzoo. 2019b. Newzoo Global Games Market Report 2019. USA: Newzoo

$\mathrm{Ng}$, B.W.M. 2001. Japanese video games in Singapore: history, culture and industry. Asian Journal of Social Science 29 (1): 139-162.

Ng, B.W.M. 2006. Video games in Asia. In The video game explosion: A history from PONG to PlayStation and beyond, ed. M.J.P. Wolf, 211-222. Westport, Conn: Greenwood Press.

Nippon. 2019. "Have eSports finally taken off in Japan?" Accessed April 2, 2020. https://www.nippo n.com/en/japan-data/h00371/have-esports-finally-taken-off-in-japan.html.

Partners, Niko. 2018. Greater Southeast Asia PC Online games report and Five year forecast. USA: Niko Partners.

Partners, Niko. 2020. Niko Partners Indonesia Spotlight Report. USA: Niko Partners.

Niko Partners. 2020a. "Game regulations in China: everything you need to know." Accessed May 1, 2020. https://nikopartners.com/game-regulations-in-china-everything-you-need-to-know/.

Penix-Tadsen, P. 2016. Cultural Code: Video Games and Latin America. Cambridge, Mass; London: MIT Press.

Rakhmani, I., and H. Darmawan. 2015. Indonesia. In Video Games around the world, ed. M.J.P. Wolf, 249-270. Massachusetts: The MIT Press.

Sambe, Y. 2009. "Japan's Arcade Games and Their Technology." Lecture Notes in Computer Science. Entertainment Computing- ICEC 2009. 5709: 338

Schleiner, A.M. 2020. Transnational Play: Piracy, Urban Art, and Mobile Games. Amsterdam: University of Amsterdam Press.

Schneider, Florian. 2018. China's Digital Nationalism. Oxford: Oxford University Press.

Schneider, Florian, and Chris Goto-Jones. 2014. "Revisiting the Emancipatory Potential of Digital Media in Asia - Introduction to the Inaugural Issue of Asiascape: Digital Asia." Asiascape: Digital Asia 1 (1-2): 3-13

Schneider, Florian, and Chris Goto-Jones. 2015. "Where is Digital Asia?" Asiascape: Digital Asia 2 (1-2): 5-10

Shaw, A. 2013. "How Do You Say Gamer in Hindi? : Exploratory Research on the Indian Digital Game Industry and Culture." In Gaming Globally. Critical Media Studies, edited by Huntemann N.B., Aslinger B., 183-202. Palgrave Macmillan, New York

Shim, Y., and D. Shin. 2016. Neo-techno nationalism: The case of China's handset industry. Telecommunications Policy 40: 197-209. 
Singapore's Department of Statistics. 2010. “Census of Population 2010.” Accessed May 1, 2020. https ://www.singstat.gov.sg/-/media/files/publications/cop2010/census_2010_release1/cop2010sr1.pdf.

Smith, O. 2017. "Mapped: Where to go if you can't be bothered to learn the language." Accessed Jan 31, 2021. https://www.telegraph.co.uk/travel/maps-and-graphics/mapped-english-speaking-countries/.

Statista. 2018. "Revenues generated by online gaming in China from 2013 to 2022." Accessed December 18, 2018. https://www.statista.com/statistics/270112/revenues-of-china-online-gaming/.

Stewart, K., and H. Choi. 2003. PC-bang (room) culture: A study of Korean college students' private and public use of computers and the Internet. Trends in Communication 11: 63-79.

Storz, C., F. Riboldazzi, and M. John. 2015. Mobility and innovation: A cross-country comparison in the video games industry. Research Policy 44: 121-137.

Suk, Sarah. 2018. "Japan embraces eSports after lagging global peers but seeks a star to put it on the map." Accessed April 3, 2020. https://www.japantimes.co.jp/news/2018/07/29/reference/japan -embraces-esports-lagging-global-peers-seeks-star-put-map/\#.XrQ_VqgzY2w.

Suttmeier, R.P., and X. Yao. 2008. Standards and the state: Chinese technology policy in an age of globalization. In China's science and technology sector and the forces of globalization, ed. E. Thomson and J. Sigurdson, 79-118. Singapore: World Scientific.

Szablewicz, Marcella. 2016. A Realm of Mere Representation? "Live” E-Sports Spectacles and the Crafting of China's Digital Gaming Image. Games and Culture 11 (3): 256-274.

Szablewicz, Marcella. 2020. Mapping Digital Game Culture in China: From Internet Addicts to eSports Athletes. Cham: Springer International Publishing.

Tech Collective. 2019. “Southeast Asia's burgeoning digital gaming market.” Accessed March 23, 2019. https://kr-asia.com/southeast-asias-burgeoning-digital-gaming-market.

Teo, Alan R. 2013. Social Isolation Associated with Depression: A Case Report of Hikikomori. International Journal of Social Psychiatry 59 (4): 339-341.

Teo, Alan R., and Albert Gaw. 2010. Hikikomori, a Japanese Culture-Bound Syndrome of Social Withdrawal? A Proposal for DSM-5. Journal of Nervous and Mental Disease 198 (6): 444-449.

Teo, Alan R., Kyle W. Stufflebam, and Takahiro A. Kato. 2014. The Intersection of Culture and Solitude: The Hikikomori Phenomenon in Japan. In The Handbook of Solitude: Psychological Perspectives on Social Isolation, Social Withdrawal, and Being Alone, ed. Robert J. Coplan and Julie C. Bowker, 445-460. USA: Wiley-Blackwell.

Tomlinson, J. 1997. "Cultural globalization and cultural imperialism. In International communication and globalization, ed. A. Mohammadi, 170-190. London: Sage.

Manh Tuan. 2016. "What is Garakei and why Japanese people still use clamshells." Accessed November 11, 2018. https://www.thegioididong.com/tin-tuc/garakei-la-gi-vi-sao-nguoi-nhat-van-dam-me-vadung-nap-gap-858148.

Wolf, M.J.P. 2008. The video game explosion: A history from PONG to PlayStation and beyond. Westport, Conn: Greenwood Press.

Wolf, M.J.P., ed. 2015. Video games around the world. Cambridge, Massachusetts: MIT Press.

Yamada, A. 2000. "Neo-techno-nationalism: How and why it grows." Accessed April, 2020. https://www. cias.kyoto-u.ac.jp/jcas/nc/yamada.pdf.

Ye, J. 2020. "Chinese mobile games take 19 of top 100 spots in USA games market in first quarter amid Covid boom." Accessed May 4, 2020. https:/www.scmp.com/tech/article/3082441/chinese-mobil e-games-take-19-top-100-spots-us-games-market-first-quarter-amid.

Phan Quang Anh is Postdoctoral Research Fellow at Department of Social Anthropology and Cultural Studies, University of Zurich (Switzerland). He obtained his Doctorate degree in Communications and New Media, National University of Singapore (NUS) in 2019, and his MA from University of Westminster (UK) specializing in Cultural and Critical Studies in 2013. His main research interests include Game Studies, Communication, and Southeast Asian Studies. His works could be found in Heliyon, Creative Industries Journal, International Journal of Asia-Pacific Studies, Asia Pacific Social Science Review, among others. 